\title{
Cardiac Health Awareness Among Women Presenting for Routine Health Checkup at Tertiary Care Center: Time Trends Over 15 Years
}

\author{
Shibba Takkar Chhabra ${ }^{1} \quad$ Gurleen Kaur $^{2} \quad$ Samir Kapoor $^{3} \quad$ Gagandeep Nagi $^{4}$ Devanshi Kajal ${ }^{1} \quad$ Mamta Bansal $^{5}$ \\ Namita Bansal ${ }^{4}$ Baljeet Kaur ${ }^{1}$ Jaswinder Kaur ${ }^{4} \quad$ Gurinder $^{1} \quad$ Rohit Tandon ${ }^{1}$ Gurbhej Singh ${ }^{1}$ \\ Bhupinder Singh ${ }^{1} \quad$ Abhishek Goyal ${ }^{1} \quad$ Naved Aslam¹ Bishav Mohan $^{1} \quad$ Gurpreet S. Wander ${ }^{1}$
}

\footnotetext{
${ }^{1}$ Department of Cardiology, Dayanand Medical College and Hospital, Unit Hero DMC Heart Institute, Ludhiana, India

${ }^{2}$ Department of Medicine, Dayanand Medical College and Hospital, Ludhiana, India

${ }^{3}$ Department of Cardiovascular and Thoracic surgery, Dayanand Medical College and Hospital, Unit Hero DMC Heart Institute, Ludhiana, India

${ }^{4}$ Department of Research and Development (Cardiology), Dayanand Medical College and Hospital, Ludhiana, India

${ }^{5}$ Department of Radio Diagnostic, Dayanand Medical College and Hospital, Unit Hero DMC Heart Institute, Ludhiana, India
}

Address for correspondence Shibba Takkar Chhabra, DM (Cardiology), Department of Cardiology, Dayanand Medical College and Hospital, Unit Hero DMC Heart Institute, Tagore Nagar, Ludhiana 141001, India (e-mail: shibbachhabra@yahoo.com).

Ind J Car Dis Wom 2019;4:79-84

\section{Abstract}

Background Women have been thought to be protected against the perils of cardiovascular disease (CVD) till late in their lives. But the literature suggests quite the opposite with CVD being a major cause of death even in young women. In contrast, the lack of awareness among women is disheartening and needs to be addressed radically.

Methods The study was designed and conducted as retrospective cohort at a tertiary care center. Data was collected from patients presenting for routine cardiac health checkup over the past 15 years. The parameters observed included age at presenting, symptoms and/or signs, plus area of residence or domicile.

Results A total of 32,831 patients presented for routine cardiac health checkup, of which 9,211 (28.1\%) patients were women and 23,620 (71.9\%) were men. On 5 yearly cumulative assessment, the mean attendance of women was $28.1 \pm 2.5 \%$ as compared with $71.9 \pm 2.6 \%$ men. Trend observed over the past 15 years revealed little change in the number of women versus men presenting for cardiac health checkup annually. Statistical significance was seen at $p<0.01$. Among the women presenting for the checkup, it was observed that most women were in the postmenopausal age group (42.8\%), followed by perimenopausal age group (34.6\%), and least in premenopausal age group $(22.5 \%)$ during the timeline of the study. A similar trend was observed in the male attendance; the input of males being higher at all instances. Noteworthy were trends of urban women (69.6\%) presenting for health checkup more often as compared with $30.4 \%$ visiting from rural residence.

Conclusions Coronary artery disease (CAD) is not uncommon in female gender. It is accompanied by varying symptom presentation with high mortality. It is seen that cardiac health awareness is significantly lacking among women as compared with men. 


\section{Keywords}

- awareness

- cardiac

- health

- preventive

- women
There are almost static trends observed over the past 15 years, especially in premenopausal age group and rural domicile. Corrective actions inclining toward campaigns and communication to distribute information on cardiac disease prevention and treatment modalities among women are needed to curb CAD. This may promote early detection of CAD leading to early interventions to promote a healthy heart among women. Recommendations and necessary actions steps for a woman oriented cardiac program are the need of the hour.

\section{Introduction}

Cardiovascular disease (CVD) has been considered since times immemorial to be a man's domain. There is a notion among women and their treating physicians that they are relatively protected from it. Recent studies indicate quite the opposite, with CVD becoming the etiological factor of every one in four deaths in women, not sparing even the young. ${ }^{1}$

Literature has enough evidence to suggest that women have a unique risk profile predisposing to develop CVD., ${ }^{2,3}$ Despite this, it is disheartening to see that women across the globe continue to be unaware of their CVD risk and rarely present for cardiac health checkup.-6

The present study aims to analyze the attendance of women for routine health checkup in the outpatient department (OPD), hereby looking at the trends of cardiac health awareness over the past 15 years.

\section{Materials and Methods}

This study is a retrospective review of records of patients treated at a tertiary care hospital of North India. The study consisted of 32,831 patients who were attending the hospital for routine cardiac health checkup during a period ranging from 2003 to 2017.

The inclusion criteria were all consecutive asymptomatic patients presenting for routine cardiac preventive health checkup. The exclusion criteria were patients with preexisting cardiac illness presenting to the OPD for the management or follow-up and symptomatic patients presenting to the OPD for the treatment.

The women were divided into three subgroups, that is, premenopausal (< 45years), perimenopausal (45-55 years), and postmenopausal (above 55 years). ${ }^{7.8}$ The men presenting to the health checkup department were also further classified in these age groups, that is, less than 45 years, 45 to 55 years, and more than 55 years.

The attendance of the male and female patients to the health checkup department was noted and the time trends were observed over 15 years. The yearly fraction of the presenting patients as well as cumulative data of attendance to the OPD was analyzed. The cumulative 15 -year time zone was subdivided into three groups of 5 years each. The three time zones were classified as time zone 1 from 2003 to 2007, time zone 2 from 2008 to 2012, and time zone 3 from 2013 to 2017. The area of living and, henceforth, the domicile of presenting population were also noted.
Data were described in terms of range; mean \pm standard deviation ( \pm standard deviation), frequencies (number of cases), and relative frequencies (percentages) as appropriate. For comparing categorical data, chi-squared $\left(\chi^{2}\right)$ test was performed and exact test was used when the expected frequency is less than 5. The Jonckheere-Terpstra and Cuzick method was used to test trend across different time periods for categorical variables. A probability value ( $p$ value) less than 0.05 was considered statistically significant. All statistical calculations were done using SPSS (Statistical Package for the Social Science) version 21 (IBM Corp.) and Stata version 12 (Statacorp LP, USA).

\section{Results}

Total 32,831 consecutive patients attended the routine cardiac health checkup during the study period from 2003 to 2017, in which 9,211 (28.1\%) patients were women and 23,620 (71.9\%) patients were men.

The attendance of males was $71.9 \pm 2.6 \%$ versus $28.1 \pm 2.5 \%$ in females throughout all the time zones (-Fig. 1).

In the time trends analysis over 15 years, a subtle increase in the percentage of women presenting to health checkup was observed $(22.10 \%$ in $2003,26.4 \%$ in $2008,29.9 \%$ in 2013 , and $29.3 \%$ in 2017 [ $\left.p=0.000, X^{2}=49.348\right]$ ). In contrast attendance of men was $77.9 \%$ in $2003,73.6 \%$ in $2008,70.1 \%$ in 2013 , and $70.7 \%$ in 2017 ( $\left.p=0.000, X^{2}=49.348\right)$.

Time trends observed over the past 15 years were nearly static and revealed low female attendance ranging from

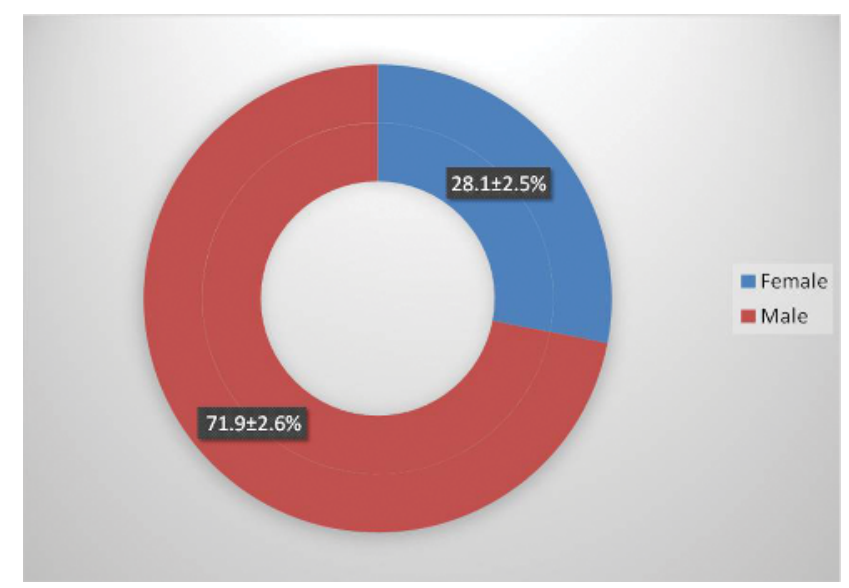

Fig. 1 Low female versus male attendance in cardiac health checkup in outpatient department. 
22.10 to $29.9 \%$ in comparison to male attendance ranging from 70.1 to $77.9 \%$. $(p=0.000)$ (-Figs. 2 and 3 ).

A cumulative assessment in the three time zones revealed that the female to male percentage was 24.2 versus $75.8 \%$, 27.1 versus $72.9 \%$, and 29.2 versus $70.8 \%$ in time zones 1,2 , and $3\left(p=0.000, X^{2}=39.212\right)$, respectively $(-$ Fig. 4$)$.

In the entire population (men and women), maximum attendance to routine cardiac health checkup was of patients $>55$ years of age, that is, $41.6 \%(n=13,667)$, followed by

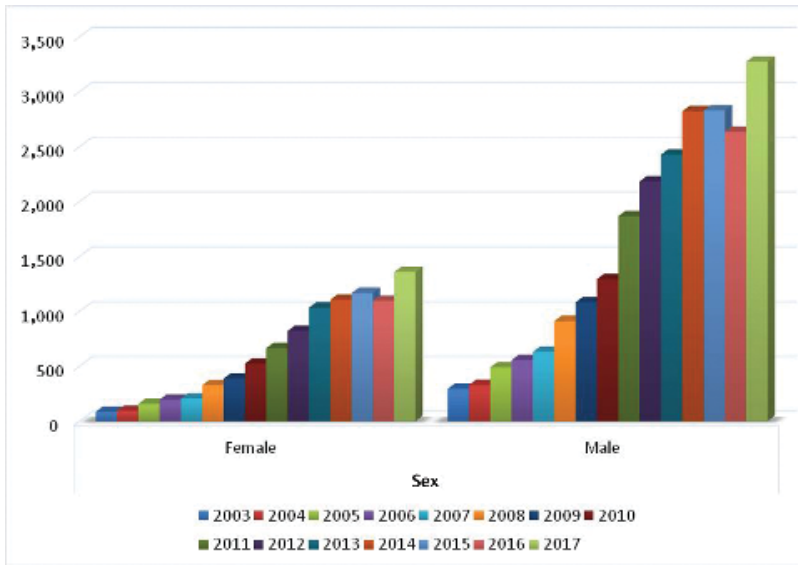

Fig. 2 Low female versus male attendance on yearly basis during study period. Slight improvement in female attendance noticed.

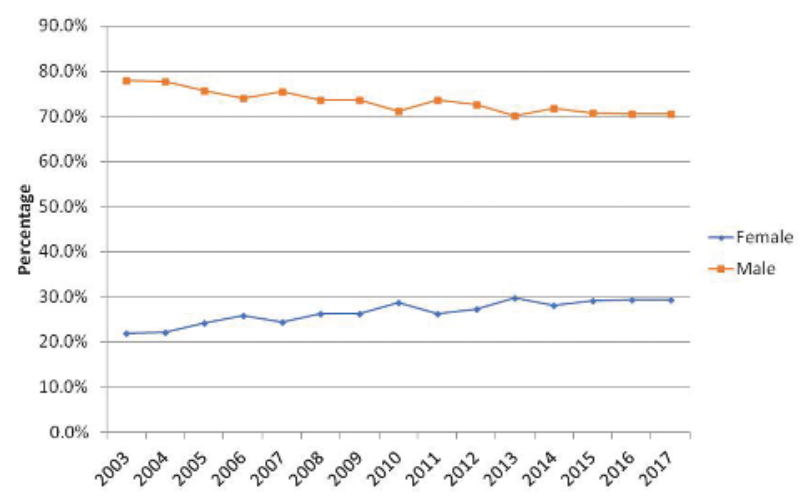

Fig. 3 Time trends analysis over 15 years with low female attendance.

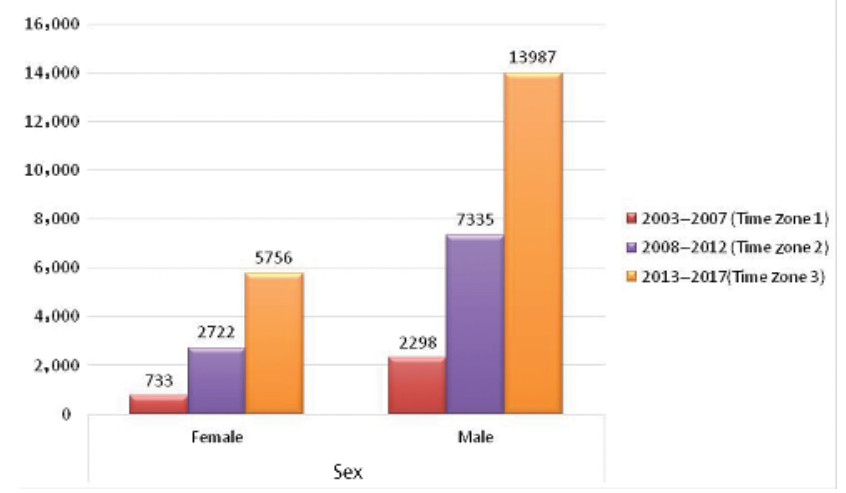

Fig. 4 Static low female versus male attendance in the three cumulative time zones. patients in the age group of 45 to 55 years, that is, 31.3\% ( $n=10,289)$, and the least percentage was of patients $<45$ years of age, that is, $27.0 \%(n=8,875)$ ( - Fig. 5).

Among the total women $(9,211)$ presenting for the checkup (28.1\%), it was observed that most women were in postmenopausal age group $(n=3945)(42.8 \%)$ followed by perimenopausal age group $(n=3,189,34.6 \%)$ and least in premenopausal age group $(n=2,077)(22.5 \%)$ during the timeline of the study.

A similar trend was observed with male attendance ( $n=23,620)$ in the corresponding age groups (i.e., 9,722 (41.2\%), 7,100 (30.1\%), and 6798 (28.8\%), respectively, [ $\left.\left.p=0.000, X^{2}=143.645\right]\right)$. The attendance of men at all age group was significantly higher versus than that of women. This was especially true in younger population (<45years) where percentage of males being $76.6 \%(n=6798)$ and input of females being $23.4 \%(n=2077)(p=0.000)$ (-Fig. 6 ).

Noteworthy was the trend of urban women (69.6\%) presenting in higher numbers as compared with women of rural domicile (30.4\%). Attendance from rural domiciles and residence showed a gradual but much needed increase in percentage across years starting from $18.8 \%$ in time zone 1 , leaping to $25.9 \%$ in time zone 2 , and further rising to $31.9 \%$

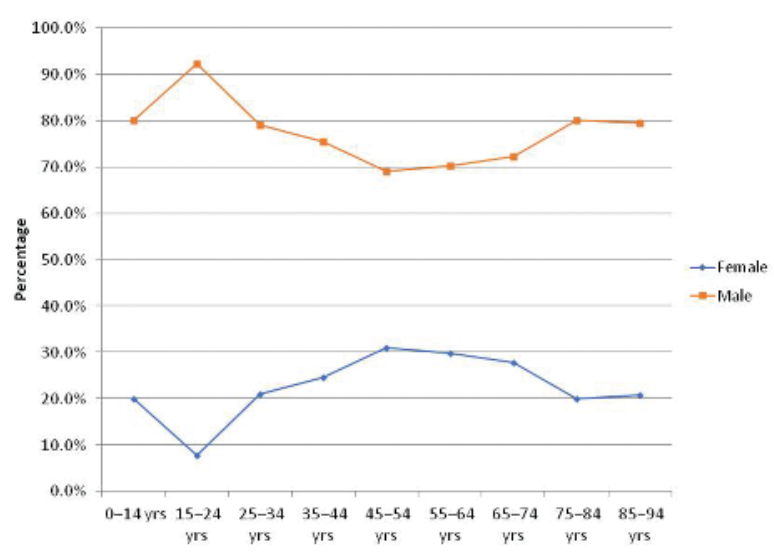

Fig. 5 Age wise trend of attendance to health checkup in outpatient department.

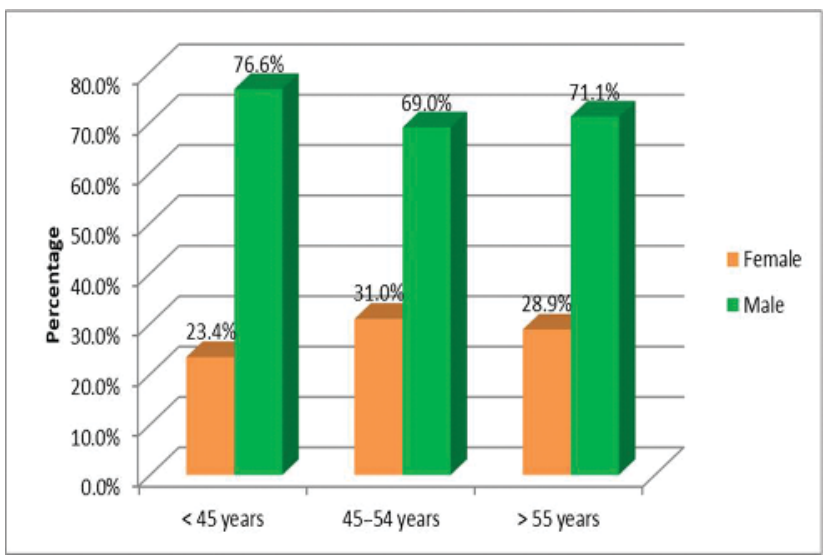

Fig. 6 Low premenopausal female attendance to cardiac health checkup in outpatient department versus male in similar age groups. 
in time zone 3 (number of patients from rural domicile $\left.\left(n_{\mathrm{R}}\right)=9,172\right)$. On the contrary, attendance from urban residences showed a decline from $81.2 \%$ in time zone 1 to $74.1 \%$ in time zone 2 to $68.1 \%$ in time zone $3\left(p=0.000, X^{2}=278.612\right)$ (-Fig. 7).

The tendency of higher postmenopausal women attendance as compared with pre- and perimenopausal was prevalent in urban as well as rural areas, that is, $>55$ years of age $\left(n_{\mathrm{R}}=1,206, p_{\mathrm{R}}=44.3 \%\right)$ (number of patients from urban domicile $\left[n_{\mathrm{U}}\right]=2,708$, percentage of patients from urban domicile $\left.\left[p_{\mathrm{U}}\right]=43.5 \%\right)$, followed by perimenopausal $\left(n_{\mathrm{R}}=898, p_{\mathrm{R}}=33.0 \%\right)$ $\left(n_{\mathrm{U}}=2229, p_{\mathrm{U}}=35.8 \%\right)$, and then premenopausal $\left(n_{\mathrm{R}}=620\right.$, $\left.p_{\mathrm{R}}=22.8 \%\right)\left(n_{\mathrm{U}}=1,285 p_{\mathrm{U}}=20.7 \%\right)\left(p=0.013, X^{2}=8.626\right)$. The attendance of women from urban domicile was higher than women of rural domicile at all instances ( $\boldsymbol{- \text { Fig. }}$ 8).

Similar trend is observed in men as well with the attendance of urban men $(p=71.9 \%, n=16507)$ being more than the rural men ( $p=28.1 \%, n=6,448)$. The maximum input was from age $>55$ years, followed by 45 to 55 years, and then $<45$ years $\left(p=0.000, X^{2}=19.154\right)$.

\section{Discussion}

This is the first study attempting time trends of women awareness toward their cardiac health in this part of the

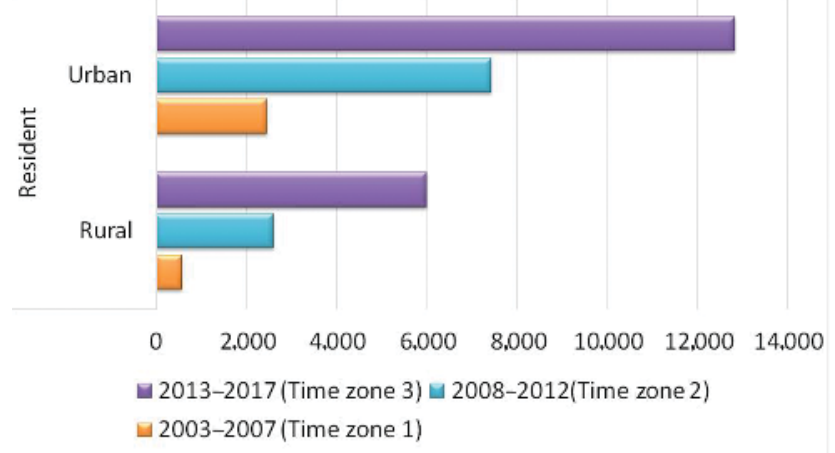

Fig. 7 Improved rural attendance over the three cumulative time zones of study.

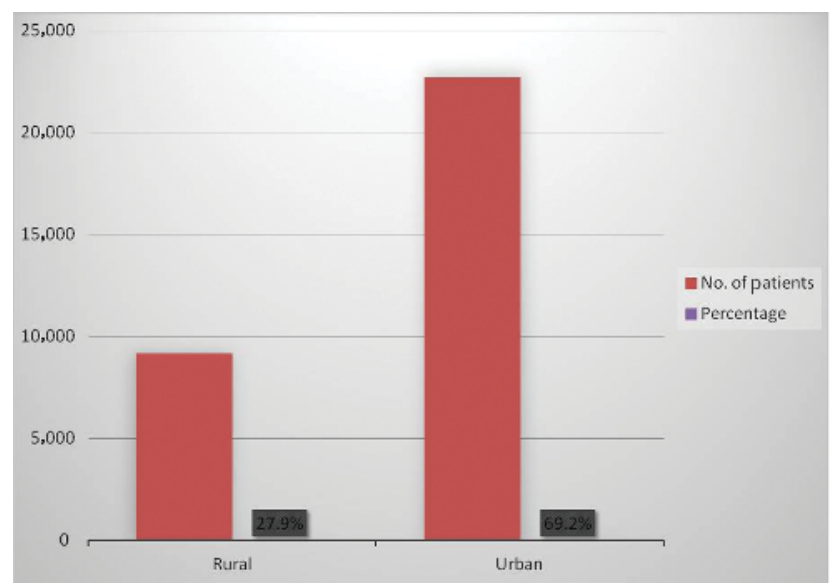

Fig. 8 Low rural attendance to cardiac health checkup in outpatient department. developing world. Since times immemorial, there has been a gender bias in assessment, management, and preventive protocols followed by women themselves and their treating physicians with regard to their CVD. ${ }^{4}$ This could be so because women might have a varied presentation that widely deviates from routine and can get easily ignored. Also, the general belief that women are protected from heart diseases prevails. Women have high mortality as compared with men of same age for occurrence of $\mathrm{CVD}^{9-13}$ along with a unique risk profile. ${ }^{14,15}$

In the present study, mean attendance of women $(28.1 \pm 2.5 \%)$ over the past 15 years presenting for routine preventive cardiac health checkup was significantly lower than that of men (i.e., $71.9 \pm 2.6 \%$ ). Encouraging to note was the subtle increase in the percentage of women attendance over the various time zones but the numbers are still significantly less. A recent survey VEDNA (visualising the extent of heart disease in Indian women) reports an increasing incidence of CVD in women (16-20\%) with a 10 to $15 \%$ rise in younger women aged 20 to 40 years. ${ }^{5}$ This was attributed to the changing lifestyle of the modern women who stressfully juggled between professional and personal lives. In spite of reported rise in CVDs in women, their attendance and awareness with regard to their cardiac health remain almost static as seen in our study.

On scrutinizing the data obtained, it was established that the maximum participation of women was from the $>55$ years (42.8\%) age group followed by 45 to 55 years (34.5\%) and the least in $<45$ years $(22.5 \%$ ), which is significantly bleak, highlighting the lack of awareness of younger women to their cardiac health. This might be a reflection of the thought process that CVD affects older women and the younger population is relatively protected. Pregnancy and autoimmune diseases are unique pathogenic factors in these younger women and can be harbingers of CVDs in the future. ${ }^{16,17}$ Pregnancy-related complications such as pre-eclampsia, gestational diabetes, maternal placental disorders, and arrhythmias can be etiopathogenic factors for future CVDs. ${ }^{16-18}$ Accordingly, the women who suffer from complications during pregnancy should be made aware of this possibility. They should be on the radar and should undergo regular cardiac health checkups to decrease the incidence of delayed diagnosis and treatment in the advent of CVDs.

Also, interesting to note is the rising trends in percentage of rural population (12.8-32.9\%) attending the health checkup, especially rural women. Though the number is still significantly low compared with urban domicile, this trend appears to be encouraging.

The finding of our study is not unknown to mankind. Probably this scenario appears to be same cross the world. A recent analysis in circulation by ACC/AHA reported that only $46 \%$ women recognized CVD as the leading cause of death in women. ${ }^{6}$ The ignorance stands among not only the women, but their treating physicians also as reported by Bairey Merz et al. ${ }^{19}$ Only $38 \%$ of women reported that their doctors had discussed heart disease with them. Health promotion campaigns like "Heart Truths" and "Red Dress" in the American continent helped improve recognition of cardiac risk in women. ${ }^{20}$ 
Necessary actions should be taken not only by health institutes but by private as well as public sectors to avoid morbidity and long-term mortality from CVDs in women. The actions should aim at primary prevention of CAD with dietary and lifestyle modification and medical therapy according to the risk profile of women. Primary health workers should be engaged to disseminate knowledge and promote regular health checkups in women of rural residence. Women health camps, heart rallies, and runs should be organized as mass level projects to bring about awareness to the masses. Similar efforts done in other developing nations have been successful. ${ }^{21}$ Cardiac health awareness seminars can be organized in educative institutions including schools and colleges for the students as well as teachers (of which women are a significant number) so as to inculcate the awareness in the early years.

The supposed limitations of our study were the assumption of premenopausal, perimenopausal, and postmenopausal phases (i.e., premenopausal-less than 45 years, perimenopausal-45 to 55 years, and postmenopausal-above 55 years) and use of convenience sampling and the collection setting. This study collected data from patients who were more available than average patients in a hospital setting. This data might not actually be corroborative with the awareness of women about their cardiac health. It is possible that women cognizant of their cardiac health are not able to reach health checkups due to lack of financial, emotional, and circumstantial support. The results might also be biased by the time series design which we have employed for attendance at the OPD.

\section{Conclusion}

Cardiac health awareness is significantly lacking among women as compared with men. There are almost static trends observed over the past 15 years; time trends especially in pre-menopausal age group and rural domicile. Hence, corrective actions inclining toward campaigns and communication to disseminate cardiac prevention and treatment modalities among women are needed to curb CAD. Effective stratification methods can be employed to cover as large population as possible by door to door or mobile van services. Health promotion should aim to create and reflect flavor of the domicile in order for the message to be understood and to be effective at a local ethnic level. Moreover, there is a need to promote early detection of CAD in order for the interventions to be effective for a healthy heart among women in North India. Recommendations and necessary steps for a woman oriented cardiac program are the need of the hour.

\section{Conflict of Interest}

None.

\section{References}

1 Xu J, Murphy SL, Kochanek KD, Bastian BA. Deaths: final data for 2013. Natl Vital Stat Rep 2016;64(2):1-119
2 Mehta LS, Beckie TM, DeVon HA, et al; American Heart Association Cardiovascular Disease in Women and Special Populations Committee of the Council on Clinical Cardiology, Council on Epidemiology and Prevention, Council on Cardiovascular and Stroke Nursing, and Council on Quality of Care and Outcomes Research. Acute myocardial infarction in women: a scientific statement from the American Heart Association. Circulation 2016;133(9):916-947

3 Aggarwal NR, Patel HN, Mehta LS, et al. Sex differences in ischemic heart disease: advances, obstacles, and next steps. Circ Cardiovasc Qual Outcomes 2018;11(2):e004437

4 Biocon puts the spotlight on heart disease in women via 'Queen of Heart' campaign. Available at http://www.pharmabiz.com/ NewsDetails.aspx?aid=76821\&sid=2. Accessed August 1, 2013

5 Mosca L, Ferris A, Fabunmi R, Robertson RM; American Heart Association. Tracking women's awareness of heart disease: an American Heart Association national study. Circulation 2004;109(5):573-579

6 Sherman S. Defining the menopausal transition. Am J Med 2005;118(Suppl 12B):3-7

7 Menopause: Full Guideline. NICE Guideline, No. 23. National Collaborating Centre for Women's and Children's Health (UK). London: National Institute for Health and Care Excellence (UK); 2015 Nov 12

8 Bucholz EM, Strait KM, Dreyer RP, et al. Editor's choice-sex differences in young patients with acute myocardial infarction: a VIRGO study analysis. Eur Heart J Acute Cardiovasc Care 2017;6(7):610-622

9 Daly C, Clemens F, Lopez Sendon JL, et al; Euro Heart Survey Investigators. Gender differences in the management and clinical outcome of stable angina. Circulation 2006;113(4):490-498

10 Jneid H, Fonarow GC, Cannon CP, et al; Get With the Guidelines Steering Committee and Investigators. Sex differences in medical care and early death after acute myocardial infarction. Circulation 2008;118(25):2803-2810

11 Shaw LJ, Shaw RE, Merz CN, et al; American College of Cardiology-National Cardiovascular Data Registry Investigators. Impact of ethnicity and gender differences on angiographic coronary artery disease prevalence and in-hospital mortality in the American College of Cardiology-National Cardiovascular Data Registry. Circulation 2008;117(14):1787-1801

12 Kunadian V, Qiu W, Lagerqvist B, et al; National Institute for Cardiovascular Outcomes Research and Swedish Coronary Angiography and Angioplasty Registries. Gender differences in outcomes and predictors of all-cause mortality after percutaneous coronary intervention (Data from United Kingdom and Sweden) Am J Cardiol 2017;119(2):210-216

13 Canto JG, Goldberg RJ, Hand MM, et al. Symptom presentation of women with acute coronary syndromes: myth vs reality. Arch Intern Med 2007;167(22):2405-2413

14 Khan NA, Daskalopoulou SS, Karp I, et al; GENESIS PRAXY Team. Sex differences in acute coronary syndrome symptom presentation in young patients. JAMA Intern Med 2013;173(20):1863-1871

15 Chhabra ST, Bali R, Kaur T, et al. Is pregnancy a risk factor for future cardiovascular events? Indian J Cardiovasc Dis Women-WINCARS 2017;2:56-62

16 Durante A, Bronzato S. The increased cardiovascular risk in patients affected by autoimmune diseases: review of the various manifestations. J Clin Med Res 2015;7(6):379-384

17 Lykke JA, Langhoff-Roos J, Sibai BM, Funai EF, Triche EW, Paidas MJ. Hypertensive pregnancy disorders and subsequent cardiovascular morbidity and type 2 diabetes mellitus in the mother. Hypertension 2009;53(6):944-951

18 Burlina S, Dalfrà MG, Chilelli NC, Lapolla A. Gestational diabetes mellitus and future cardiovascular risk: an update. Int J Endocrinol 2016;2016:2070926 
19 Bairey Merz CN, Andersen H, Sprague E, et al. Knowledge, attitudes, and beliefs regarding cardiovascular disease in women: the women's heart alliance. J Am Coll Cardiol 2017;70(2):123-132

20 Mosca L, Ouyang P, Hubel CA, Reynolds HR, Allison MA. Go Red for Women Strategically Focused Research Network Centers. Circulation 2017;135(6):609-611
21 Rubinstein A, García Martí S, Souto A, Ferrante D, Augustovski F. Generalized cost-effectiveness analysis of a package of interventions to reduce cardiovascular disease in Buenos Aires, Argentina. Cost Eff Resour Alloc 2009;7:10 